\title{
Making Use of Educational Research in Higher Education-Academic Teachers Engaged in Translational Research
}

\author{
ABSTRACT \\ Why do not academic teachers more frequently use results from education, psychology, \\ cognitive sciences, and related fields while planning, carrying out, and evaluating teaching? It \\ has been argued that if only they did, education would improve. It has further been argued \\ that results from these fields are not communicated in ways suitable for teachers from other \\ disciplines, and therefore there is a need for translation. If the results from these fields were \\ translated, it has been proposed, their use would increase with positive effects on education. A \\ question remains: who should do the translation? This study investigates whether early career \\ academics in engineering and technology can find, translate, and make relevant use of \\ research into education, psychology, and related fields within written reports. Results show \\ they can. Therefore, it is argued, translation itself will not increase the use of this type of \\ research. Other explanations for the problem are discussed.
}

\section{KEYWORDS}

translational research, academic teachers, educational research, early career academics

There is a difference in expectations on how research is being used in the world of education and how it is used in the world of medicine. When I am ill and seek medical advice, I expect that the doctor is up to date with the research in the relevant field. I want to be treated according to the latest evidence. When I am being taught, however, this is not something I can expect, at least not if I assume that teachers to design, carry out, and evaluate their teaching according to the latest research in education and related fields. Although such research produces numerous articles on all aspects of learning and teaching, in my own experience, as an academic teacher and as a teacher of other academic teachers, is that this research is mostly neglected, or at least not used, by teachers. Instead, they rely on local teaching tradition, planning, teaching, and evaluating in similar ways over the years.

Thus, there appears to be a weak link between what is known in educational, psychological, and cognitive research about learning and the extent to which this knowledge is used by practicing teachers. It has been argued that teaching and student learning would improve significantly if only teachers made more use of this research. For example, Roediger and Pyc (2012) point out that all this research already exists for free and that there would be a lot to gain if only teachers became aware of relevant research and started to act upon it, much like medical doctors are expected to do.

Why then do teachers fail to use educational research to continuously enhance teaching and student learning? One answer put forward in the literature is that educational and related research is not 
accessible enough. There is a gap between researchers and teachers, it is argued, a gap caused by a communication problem. Harvard professor Catherine Snow has formulated it like this: "Perhaps the most often cited [problem] is the difficulty of getting research into practice: well-meaning researchers generate ideas, findings, practices, and programs that are not optimally communicated to practitioners, and often not optimally designed for a use in practice" (quoted in Bucuvalas, 2011 [my emphasis]).

The findings from educational and related research can of course be assembled, summarized, and translated to made more accessible for teachers. To do this would be a practice in itself. In the health sector this solution has generated translational research. Under banners like "from bench-to-bedside" or "from lab to clinic," research results have been reformulated to become more user-friendly for health practitioners and thereby possibly increase the likelihood that new insights contribute to better treatment of patients. An equivalent strategy can be applied in education. Results from educational research can be translated to match the needs of teachers and thus lead to better teaching and student learning. According to Woolf (2008), this translation can be carried out by means of two models: either (a) results from research are developed into new methods and procedures, which are then handed over to practitioners as ready-made products; or (b) through a more complex method whereby the research result is not only handed over but followed all the way through into the practice. The second model is further described by Daniel (2012), who suggests "the following translational steps for moving from the lab” (p. 251):

1. Exploration of promising findings in the lab-yields hypothesis for practice

2. Careful experimentation in select classroom contexts - yields promising results

3. Development and design of classroom/teacher-friendly methods integrating promising principle into everyday practice (and encourages practitioner fidelity to practice)

4. Coordinated experimentation in more representative and complex settings (clinical trials, etc.) _yields best practice

5. Dissemination and continued refinement (Daniel, 2012, p. 251)

This elaborated method is necessary, Daniel concludes, to maintain the "appreciation for the complexity of the context in which one hopes to apply promising principles” (p. 252).

Even though the discussion as summarized above has been suggested foremost for K-12 education, it also appears relevant for higher education. If results from educational research were to reach teachers and teaching, some practices would most likely look different. We know that teaching practices in universities are often rooted in traditions formed more or less without interaction with modern educational theory (Trowler, 2008; Mårtensson, Roxå, \& Olsson, 2011). To make these results a living and debated part of university teachers' everyday conversations and thinking would most likely be a good thing. Potentially, it could lead to an ongoing development of teaching similar to the development of practices and thinking in most parts of the health sector.

However, to put this vision into practice, many questions need answering: Who is best suited to translate educational research so that is has an impact on the teaching practices within higher education? Is it the educational researcher, who is in control of research results, or is it the teacher, who is in control of teaching practices; or is it perhaps a new group of practitioners specialized in translating educational research? Further, is translation the best way to solve the problem? If results from educational research were translated, made more accessible, and presented to teachers, would they then be used? Other questions concerning the impact from educational research on teaching practice can be formulated: Is 
the impact linear, so that more results in use means better teaching and student learning? Is there an optimum point of research integration at which teachers will develop their practices best. Put differently, can teaching practices in fact decrease in quality if too much research is considered?

Obviously, there is a need for further research on these issues. This article investigates whether a group of young academic teachers are capable of finding and applying results from educational research in a meaningful way. It is a way of testing the hypothesis that educational research is too specific, too complex, and too inaccessible for teachers from other disciplines. The specific question being asked is as follows: If instructed to use references while discussing issues in education, is a group of early career academic teachers able to find and to integrate research from psychology, education, and cognitive science in a meaningful way despite coming from a different disciplinary background?

If the answer is no, educational research, its design and results, is arguably too complex or alien for academic teachers to use. Thus, a negative answer would strengthen arguments for the establishment of translational research and practices in this area. If the answer is yes, the argument that translation is the solution might need to be reassessed. There may be reasons why this research is not used by teachers, other than that it is simply a problem of communication.

\section{RESEARCH CONTEXT AND MATERIAL}

Twenty reports from an introductory pedagogical course, Introduction to Teaching and Learning in Higher Education, for doctoral students in engineering have been analyzed in order to reveal if and how references are made to educational research. The context is a faculty of engineering within a traditional Swedish university. The faculty is research-intensive, with two-thirds of its budget coming from external research funding, but also with a reputation of using the Scholarship of Teaching and Learning (SoTL) as a change strategy. The pedagogical course, which is offered four to five times per year, is mandatory for all doctoral students, almost all of whom teach 20 percent of their working time. The participants use 80 working hours for the course, which rewards them a certificate to include in their doctoral exam. During 2013, the course was offered four times, two times in Swedish and two times in English. When the course is offered in English, the participants are almost exclusively international students from all over the world. The course has been in operation for more than 10 years and has consistently been highly appreciated by participants.

The course consists of two parts. The first part is a full week in class, in which various educational topics are introduced: deep and surface approaches to learning (Marton \& Booth, 1997); constructive alignment and the SOLO-taxonomy (Biggs \& Tang, 2007); communication in and outside the classroom, assessment and examination, evaluating teaching (Ramsden; 2005); and teaching careers, including ways to convey pedagogical competence through a teaching portfolio (Olsson \& Roxå, 2013). During this first week, the participants work in groups of four or five, based on disciplinary area, such as chemistry, physics, or computer science. This discipline-sensitive design is explicitly explained to participants as a way to allow them to assess educational concepts against the needs of their respective disciplines. Teaching throughout this week is a mix of methods, such as workshops, peer teaching, seminars, and reading.

The second part of the course is a project carried out in groups (the same groups as in the first part of the course) and reported through a scholarly report, which is peer-reviewed by other groups within the course. Twenty such reports (all reports produced during 2013) constitute the material for this paper (11 written in English and nine in Swedish). 
As a starting point for the projects, the participants receive this written instruction:

Each group chooses/negotiates a common project idea or case study of interest. The project can process something that is common to all in the group or something that only some of the group members have in common, or even something that is related to only one of the group members. The project should preferably be about a self-perceived educational situation that contains some kind of problem or challenge. It can of course also be something completely new to the group to examine.

The project report must: demonstrate an understanding of the problem/theme and suggest an analysis of it; relate to relevant course content and theory; include a literature analysis related to the problem/theme; present solutions to the problem situation and a critical review of these; have correct referencing; have a title that shows the discussed pedagogical problem; have abstract and keywords; and be around 8-10 pages.

The participants are explicitly instructed to upload their reports to a database hosting all reports written by previous participants in the course and other colleagues in the faculty. In 2013, the database contained approximately 500 written pieces authored by teachers in the faculty.

The 20 reports cover a range of areas relevant for teachers in the field of engineering. Below follows a list of all report-titles (Exhibit 1) (the translation from Swedish are mine).

\section{Exhibit 1. Student report titles}

1. Studenters elektronikanvändning under föreläsning-Hanteringsstrategier och effekter på studenternas inlärning (Students' use of electronic devices during lectures-Strategies in use and effects on student learning.)

2. Strategier att hantera den omotiverade studenten (Strategies to handle students with low motivation.)

3. Att engagera tysta elever under laborationer (Engaging silent students during laboratory exercises.)

4. Motiverande förberedelseuppgifter-inns de? (Motivating prep-assignments-Do they exist?)

5. Programspecifik kurs för hållbar utveckling (A curricular-sensitive course in sustainable development.)

6. Web-based teaching and learning: A short empirical study with a focus on group work

7. The issue of surface learning in labs-How to promote deeper learning from both educators and students' perspectives

8. A study of the underlying reasons and consequences of large laboratory groups

9. Challenges in teaching international students: Group separation, language barriers and culture differences

10. The role of examination in quality learning

11. Kvaliten på handledning av rapportskrivande under examensarbete (The quality of supervision during authoring of reports or master-theses.)

12. Undersökning av kursutvecklings och kursutvärderingsprocesser på LTH (An investigation of course development and student evaluation of courses within the faculty of engineering.)

13. Hur man skapar goda förutsättningar inför en laboration (How to create optimal conditions for a laboratory exercise.)

14. Challenges of constructive alignment in engineering higher education 
15. Den gäspfria föreläsningen—Om att aktivera studenter i plenum. (The yawn-free lecture-How to activate students during plenary teaching.)

16. Teaching students having different level of prior knowledge and motivation

17. Communication between educational and industrial enterprises: Industrial $\mathrm{PhD}$ students, the missing link

18. Engaging and maintaining students' interest during lectures

19. Contemplations of student perspectives toward online based learning environments

20. A course assessment using SOLO and Bloom's taxonomies in light of the constructive alignment methodology: A case study

\section{RESEARCH PROCEDURE}

Step 1

To identify the disciplinary origin of the work integrated in the project reports, the reference list in all 20 reports were grouped into nine groups. Table 1 presents these groups.

\section{Table 1. The disciplinary origin of references as they appear in the lists of references in the $\mathbf{2 0}$ reports}
A. International journals related to education, psychology, higher education, cognitive sciences, and related areas.
B. Discipline based international journals (chemical education, computer science education, and others).
C. Books and international reports.
D. National reports and journals.
E. National and international conferences.
F. Material produced by teachers in the faculty.
G. Web-based sources.
H. Other material.
I. Unclear origin.

The references from group A are of particular interest, since the research question asks specifically about the participants' capacity to handle research from these disciplinary areas.

\section{Step 2}

In order to exhibit the range of journals used in the reports, a list of all the journals represented in the references in group A was constructed.

\section{Step 3}

Step 3 involved an analysis of how the references from group A were used. The principle applied follows the idea that references can be used just for the sake of it, that is, they can be placed in the text simply to impress the reader. But they can also be used to back up general or specific claims, and in doing so they can also be quoted or summarized. Finally, references can be used to frame an entire report, that is, introduced as an organizing element in the beginning of the report and linked back to in the end. Thus, this more qualitative step in the analysis applies the following categories.

The reference

- is just placed in the text once without a link to a claim, 
- is used as in A, but more than once;

- is used to back up a general claim made by the author;

- is used to back up a specific claim made by the authors;

- is used and quoted to back up a claim made by the authors;

- is summarized so that one aspect is used (e.g., the results, bits of research procedure is included);

- is summarized so that several aspects are used; or

- is used to frame the report or to construct a perspective followed throughout the report.

The categories were constructed during an iterative process of reading and rereading the reports. (During this process, linguistic expertise was consulted.)

\section{RESULTS}

\section{Types of references listed in the list of references in the reports}

The 20 reports contain a total number of 344 references in their list of references (Figure 1.). The most frequent category of references is B, discipline-based international journals (95). The second most frequent category is $\mathrm{C}$, books and international reports (84). Category A references (education, psychology, and so on) appear 66 times in the 20 lists of references.

\section{Figure 1. The total number of references in respective category}

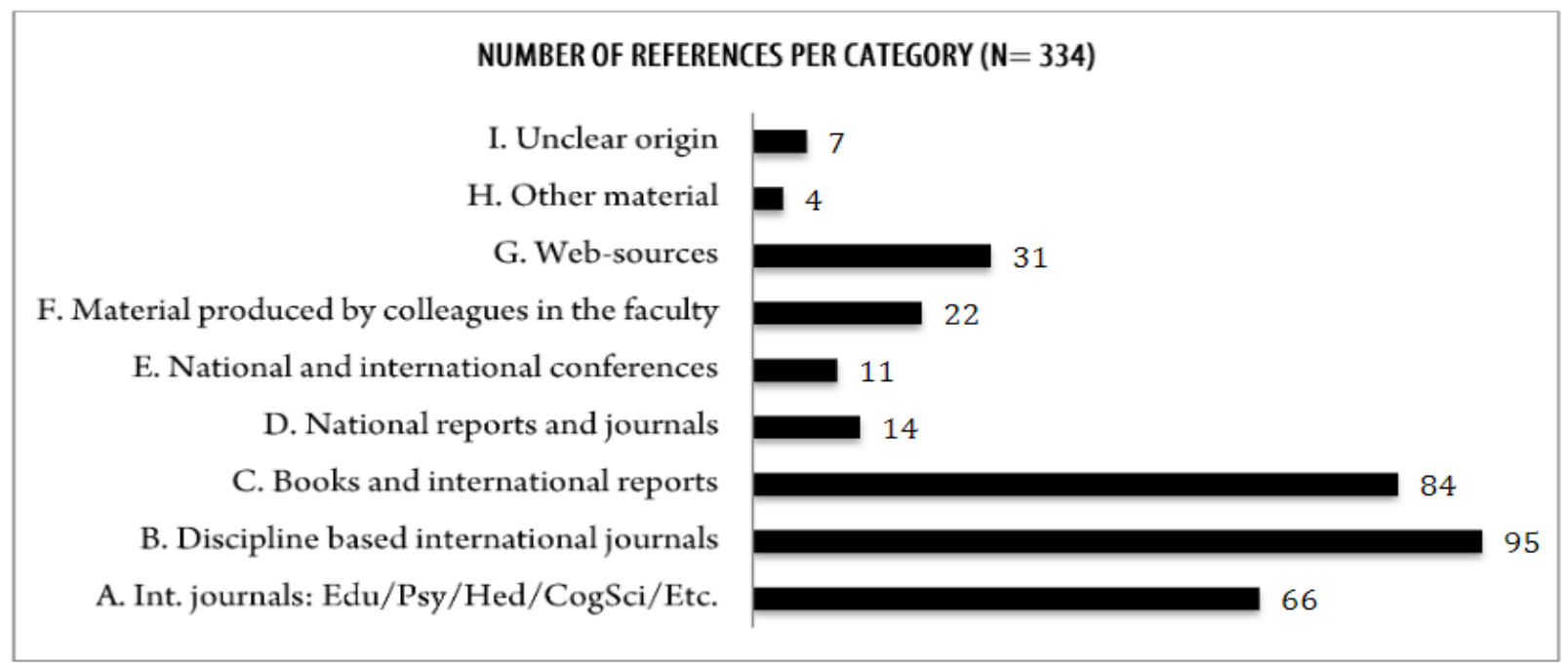

The relationship between the number of references used from each category reveals insight on how the participants prioritise when looking for references. They are instructed to use references, but they are not advised as to what type of references, where to find them, or how to use them. Category $\mathrm{F}$ is interesting since the participants are specifically directed towards the existing database. Furthermore, there is a bias in relation to group C since each participant received a copy of Biggs and Tang (2007) at the start of the course. Considering this, it is striking that references from category A are so frequent. 


\section{The total number of references per report and from category $A$}

Figure 2 shows that there is considerable variation in the number of references among the various reports. For example, Report 1 lists 43 references while Report 8 only lists eight references. A similar variation appears in relation to the category of references we are interested in here (Category A). About half of the reports list only two references or fewer from this category.

\section{Figure 2. The total number of references (dark grey staples) and references from category A (light grey staples)}

\section{NUMBER OF REFERENCES IN LIST OF REFERENCES AND NUMBER OF REFERENCES FROM PSYCHOLOGY, EDUCATION, HIGHER EDUCATION, ETC.}

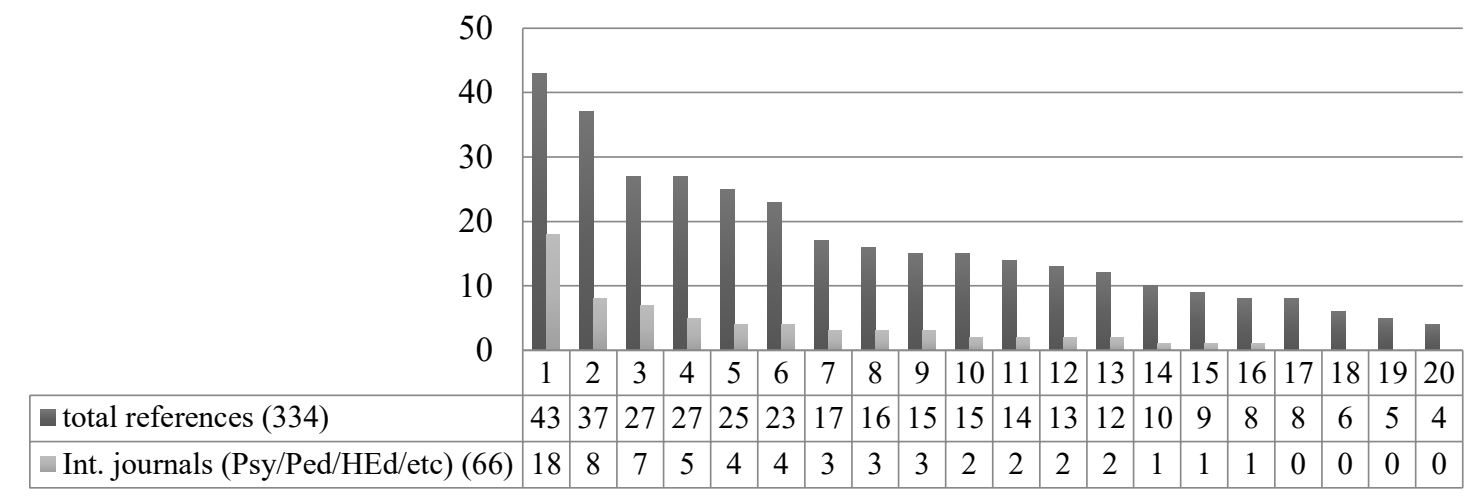

Journals from category A appearing in the lists of references

Forty-six various journals from the areas of education, psychology, higher education, cognitive science, and the like appear in the lists of references (Exhibit 2 provides a complete list). Nothing in the written instruction directed the participants toward these particular journals. Consequently, the participants must have found them themselves. The most common journals include Studies in Higher Education (six times) Higher Education Research and Development (five times).

\section{Exhibit 2. Journals from category A referred to in the report}

Active Learning in Higher Education

Adult Learning

Assessment in Education: Principles, Policy \& Practice

Assessment \& Evaluation in Higher Education (2 times)

Australian Journal of Teacher Education

Behavioral Brain Research

Business Communication Quarterly

Communication Education

Contemporary Educational Psychology

Educational Horizons

Educational Research Review

European Journal of Higher Education

Feminist Teacher

Higher Education (3 times)

Higher Education Research \& Development (5 times)

Innovations in Education and Teaching International (2 times) 
Innovations in Education \& Training International

International Education Journal

Journal of College Reading and Learning

Journal of Experimental Psychology

Journal of the First-Year Experience \& Students in Transition

Journal of Further and Higher Education

Journal of Higher Education

Journal of the Learning Sciences

Journal of Pedagogy and Psychology

Journal of Personality

Journal of Research in International Education

Learning and Individual Differences (2 times)

Learning and Instruction

Mediterranean Journal of Social Sciences

Nature

New Directions for Teaching \& Learning (3 times)

Psychological Bulletin

Psychological Inquiry

Psychological Review

Research in Higher Education (3 times)

Research on social work practice

Science

Studies in Higher Education (6 times)

Teachers and Teaching: Theory and Practice

Teaching in Higher Education

Teaching and Learning in Higher Education

Teaching of Psychology (3 times)

Reading Teacher

Trends in Cognitive <complete title>

\section{How references from category $A$ are used in the text}

The 66 references from journals in education, psychology, higher education, and cognitive sciences in the lists of references are used 99 times, and arguably they are used intentionally (Table 2). The most common usage is to back up a claim. In 30 cases the reference back up a general claim made by the authors, while in 41 cases they back up a specific claims. Quotes and summaries appear in 24 cases. The recurrent uses are to quote or to summarise elements in the reference, describe a taxonomy of some kind, or list recommendations formulated in the original article. In four reports, the authors have used a specific reference to frame the text at the outset and returned to this frame in the end of the report.

Table 2. How references from educational research and related areas are used in the reports. In total, references from this category are used 99 times in the 20 reports

\begin{tabular}{|c|c|}
\hline THE REFERENCE & \\
\hline is just placed in the text once without a link to a claim & 0 \\
\hline is used as in $\mathrm{A}$, but more than once & 0 \\
\hline is used to back up a general claim made by the author & 30 \\
\hline
\end{tabular}




\begin{tabular}{|l|r|}
\hline is used to back up a specific claim made by the authors & 41 \\
\hline is used and quoted to back up a claim made by the authors & 5 \\
\hline $\begin{array}{l}\text { is summarized so that one aspect is used (e.g., the results, bits of research } \\
\text { procedure is included) }\end{array}$ & 11 \\
\hline is summarized so that several aspects are used & \\
\hline $\begin{array}{l}\text { is used to frame the report or to construct a perspective followed throughout the } \\
\text { report }\end{array}$ & \\
\hline Total & \\
\hline
\end{tabular}

To further show how references are used, examples are offered below. The examples are organised according to how the references are used. (I note that none of the students in the group studied placed references in the text without a link or a claim, either once or multiple times.)

The reference is used to back up a general claim

In report 18 (Engaging and maintaining students' interest during lectures), the authors claim that "participating in online discussion before class is a way of helping students to prepare for the in-class discussion, to learn to formulate questions, and it also provides feedback to the teacher (Lineweaver, 2010)" (Report 18, p. 8).

The reference is used to back up a specific claim made by the authors

In report 19 (Contemplations of student perspectives toward online based learning environments), the authors claim that "Direct feedback or academic interaction is another critical aspect of e-learning (Hughes \& Daykin, 2002)” (Report 19, p. 5).

The reference is used and quoted to back up a claim made by the authors

In report 16 (Teaching students having different level of prior knowledge and motivation), the authors write, "Nowadays it is already generally acknowledged that prior knowledge is one of the most crucial factors in teaching. Dochy, Rijdt, and Dyck (2002) even said: 'prior knowledge is still the most important student variable in learning-(Report 16, p. 3).

The reference is summarized so that one aspect is used (e.g., the results and bits of the research procedure is included)

In report 13 (Hur man skapar goda förutsättningar inför en laboration [How to create optimal conditions for a laboratory exercise]), the authors discuss how the general understanding for chemistry interacts with an understanding of how a specific laboratory exercise should be carried out. They argue that students often seek a punctuated understanding of the procedure rather than an overall picture, and they continue: "Roth et al. (1997), also found that an insufficient understanding of how the exercise at hand should be carried out negatively effected a general understanding of chemistry to develop" (Report 13, p. 7).

The reference is summarised so that several aspects of it are used

In report 9 (Challenges in teaching international students: group separation, language barriers and culture differences), the authors summarise several aspects from a reference and continue to discuss their implications for the report at hand: "According to Volet and Ang (1998), both local and 
international students preferred to work within their own groups when working on assignments. They gave four types of reasons for not mixing when doing group work: cultural-emotional connectedness, language, pragmatism, and negative stereotypes" (Report 9, p. 5). The authors then summarise the four types of reasons and continue, again citing Volet and Ang (1998) as showing "that, after a successful multicultural group work, students realize that cultural differences are of less importance than having a common goal and a mutual commitment to invest time and energy in the task" (Report 9, p. 5).

\section{The reference is used to frame the report or to construct a perspective followed throughout the} report

In report 14 (Challenges of constructive alignment in engineering higher education), the authors use the concept of constructive alignment and refer to Biggs (1996; 2012) and Biggs and Tang (2007) to frame their entire report. "[T] he purpose of this study is to find the answers to the following research questions: (1) Do teachers actively work with constructive alignment when designing courses?, and (2) What are the challenges of implementing constructive alignment in practice experienced by teachers in engineering higher education?" (Report 14, p. 2). After a literature review, eight courses are selected for analysis. Intended learning outcomes, teaching activities, and examination are analysed prior to individual interviews with each course coordinator. The authors conclude that "course coordinators are not primarily guided by the concept of constructive alignment. We have also identified additional challenges, besides those discussed in literature, that negatively affect the alignment" (Report 14, p. 11).

\section{Summary of results}

Of the 344 references appearing in the lists of references in the 20 reports, 95 are from journals, such as those focused on chemical education and computer science education; 84 are from books and international reports; and 66 are from education, psychology, higher education, cognitive science, and other related areas. Only 22 references come from the database with reports produced by colleagues in the same faculty, a source explicitly pointed out for the participants writing the reports.

Nine out of 20 reports list three or more references from education, psychology, higher education, cognitive science, and other related fields. Four reports do not include references from this category. In the reports, references from these areas are used 99 times. Four reports use references to frame the entire report. In all, the 66 references originate from 46 different journals. These results support a claim that the referencing described is intentional, meaningful, and deliberate, with an emphasis on references backing up specific or general claims.

\section{DISCUSSION}

This study is part of a wider discussion concerning teachers' use of educational research and strategies aimed at increasing this use. The introduction summarizes parts of this wider discussion and zooms in on the question of translation, especially: who is best suited to translate research from education (and other areas) into teaching practices? Against this background the study poses the question: If instructed to use references while discussing issues in education, is a group of early career academic teachers able to find and to integrate research from psychology, education, higher education, and cognitive science in a meaningful way despite coming from a different disciplinary background?

The results indicate that the current sample of early career academic teachers (doctoral students in technology and engineering) are capable of finding and meaningfully use results from research in 
education (and related areas), at least if they are instructed to. The results support a claim that academic teachers in general are capable of using educational research without having it translated for them. At least this is true in a formal professional development activity in the form of an assignment consisting of a report about teaching and/or student learning. However, from this study we do not know the level of understanding the references inspire in the participants or how this relates to prior knowledge of this kind of material, neither do we know how or even if at all educational research is used in the collegial contexts where these academics work. We know from the literature (Ginns, Kitay, \& Prosser, 2010) that the collegial context to which an academic teacher returns from professional development activities plays an important role for how this knowledge is utilised.

The variation in how many references the groups include in the reports is striking and cannot be explained as an effect from the instruction since all groups received the same instruction. An alternative explanation is that various groups had different competences, some of them might have had relevant prior knowledge and others did not. If so, a reasonable expectation is that some groups (those with less relevant prior knowledge) would use more references from discipline-focused journals such as the Journal of Chemical Education and fewer journals from education to compensate for the lack of prior knowledge. To use discipline-based journals about education would simply appear more natural than crossing disciplinary boundaries into social science. But they do not; instead, the groups using few references in education also use fewer references more generally (Figure 2 ). Thus, a more likely explanation is that the variation is caused by a variation in how meaningful the task appeared to the participants. Groups using more references from education and related areas do so because they find it meaningful. Therefore, a likely answer to the research question is that academic teachers in the area of technology and engineering can find and make meaningful use of research from education and related areas if they End it meaningful to do so.

The question about what influences the meaningfulness of educational research for academic teachers can be discussed further. Scholars have argued that academic teachers are influenced by culturally formed local teaching and learning regimes (Trowler; 2008) and that these collegiallyconstructed and maintained regimes hugely affect what teachers find meaningful to consider in their everyday teaching practices. It has been further argued that the specific work groups in which teachers are a part, so-called microcultures, have an overall effect on academic teachers' willingness to learn about education (Roxå \& Mårtensson, 2015). From this perspective, strategies for enhancing the value of educational research in academic teaching should consider the sociocultural context in which individual teachers are active. If various microcultures have a tradition of devaluing or neglecting educational research as a resource during the planning of teaching through to evaluating its effect, then simply making such research more accessible will not help.

To sum up, it is not a matter of more effectively communicate the results to the teaching practitioners, as implied by Catherine Snow. It is more likely that meaningfulness plays an important part and that this is governed more by traditions and patterns of communication within the various working contexts and by institutional incentives like promotion, than in the format of the message sent by educational researchers.

This is not to say, however, that translation as such is without value. On the contrary, many of the references found in the material are textbooks or other sources specifically constructed to be accessible for academic teachers. Even the course itself and the actions of those teaching it were 
designed to make learning possible, an act governed by ambitions to translate results from educational research and make them as meaningful as possible to the participants. It might still be that the novices in education among the participants benefitted more from the translated material than did those with extended knowledge about education and psychology.

\section{FURTHER RESEARCH}

Further questions emerging from this study concern, first of all, the link between the use of educational research in reports about teaching and the use of the same references in the daily teaching practice. This issue has been debated and researched extensively by academic developers and the results are mixed (Roxå \& Mårtensson, 2015). Even so, it would be interesting to follow early career academics as they return to their collegial contexts and see whether the references used in the reports may or may not play a part in everyday thinking and practicing and whether such a use or even understanding would be related to previous studies in education, psychology, and similar subjects. Second, the issue of who is best suited to translate results from educational research remains open. However, as discussed in this study, researchers exploring this area should consider meaningfulness as an important aspect. It is also important to see that whoever is doing the translation is linked to power. The party selecting material for and doing the translation will have a major influence on its implementation - that is, this party will gain power over the teaching practice. If researchers in education are responsible for the process, it would most certainly look different than it would if teachers or a group of practitioners specialised in translation were responsible for it. For this reason, power issues should be included in any major translation strategy or research program. Third, even in this limited study, the process of making results from educational research an active force in academic teaching appears as hugely complex. Therefore, the underlying assumptions of projects related to translation of educational research should be scrutinized with a special interest for how the envisioned changes will be realized. In this context it is interesting to reconsider Catherine Snow's argument, quoted in the introduction, that the results should be communicated to teaching practitioners; it is interesting to see how this claim deviates from most current views on learning. Learning is commonly seen, not as a process of transmission but as a process where the learner constructs knowledge influenced by what he or she finds meaningful. So, it is likely that if academic teachers will ever use more results from educational research, they will do so only if the material appears as meaningful to them. As discussed above, this, in turn, is a process including many steps, among which translation of research results most certainly is one.

\section{ACKNOWLEDGEMENTS}

I thank Lene Nordrum, associate professor at English studies at Lund University for valuable advice during the analysis of how references are used in text.

I also thank all the participants in the course Introduction to Teaching and Learning in Higher Education and inform readers that I have considered all relevant ethical guidelines at Lund University for this type of research.

Torgny Roxå is an associate professor at Lund University Faculty of Engineering, Sweden. He has worked for 30 years as an academic developer. 


\section{REFERENCES}

Biggs, J. (1996). Enhancing teaching through constructive alignment. Higher Education, 32(3), 347-364. https://doi.org/10.1007/BF00138871

Biggs, J. (2012). What the student does: Teaching for enhanced learning. Higher Education Research \& Development, 31(1), 39-55.https://doi.org/10.1080/0729436990180105

Biggs, J., \& Tang, C. (2007). Teaching for Quality Learning at University (3rd ed.). Maidenhead: Society for Research into Higher Education.

Bucuvalas, A. (2011, January 26). Strategic education research partnership. An interview with Shattuck Professor Catherine Snow [Web log post]. Retrieved from https://charttesl.wordpress.com/2011/01/26/

Daniel, D. (2012). Promising principles: Translating the science of learning to educational practice. Journal of Applied Research in Memory and Cognition, 1(4), 251-253. https://doi.org/10.1016/j.jarmac.2012.10.004

Dochy, F., de Rijdt, C., \& Dyck, W. (2002). Cognitive prerequisites and learning. How far have we progressed since Bloom? Implications for educational practice and teaching. Active Learning in Higher Education, 3(3), 265284.https://doi.org/10.1177/1469787402003003006

Ginns, P., Kitay, J., \& Prosser, M. (2010). Transfer of academic staff learning in a research-intensive university. Teaching in Higher Education, 15(3), 235-246.https://doi.org/10.1080/13562511003740783

Hughes, M., \& Daykin, N. (2002) Towards constructivism: investigating students' perceptions and learning as a result of using an online environment. Innovations in Education and Teaching International, 39(3), 217224.https://doi.org/10.1080/13558000210150036

Lineweaver, T. (2010). Online discussion assignments improve student's class preparation. Teaching Psychology, 37(3), 204-209. https://doi.org/10.1080/00986283.2010.488546

Marton, F., \& Booth, S. (1997). Learning and Awareness. Mahwah: Lawrence Erlbaum.

Mårtensson, K., Roxå, T., \& Olsson, T. (2011). Developing a quality culture through the Scholarship of Teaching and Learning. Higher Education Research \& Development, 30(1), 51-62. https://doi.org/10.1080/07294360.2011.536972

Olsson, T., \& Roxå, T. (2013). Assessing and rewarding excellent academic teachers for the benefit of an organization. European Journal of Higher Education, 3(1), 40-61. https://doi.org/10.1080/21568235.2013.778041

Ramsden, P. (2005). Learning to Teach in Higher Education (2nd ed.). London: RoutledgeFalmer.

Roediger, H., \& Pyc, M. (2012). Inexpensive techniques to improve education: Applying cognitive psychology to enhance educational practice. Journal of Applied Research in Memory and Cognition, 1(4), 242-248. http://dx.doi.org/10.1016/j.jarmac.2012.09.002

Roxå, T., \& Mårtensson, K. (2015). Microcultures and informal learning: A heuristic guiding analysis of conditions for informal learning in local higher education workplaces. International Journal for Academic Development, 20(2), 193-205. https://doi.org/10.1080/1360144X.2015.1029929

Roth W-M., McRobbie C, Keith B., Lucas K., \& S. Boutonne S. (1997). The local production of order in traditional science laboratories: A phenomenological analysis. Learning and Instruction, 7(2),107-136. https://doi.org/10.1016/S0959-4752(96)00013-8

Trowler, P. (2008). Cultures and Change in Higher Education: Theories and Practice. London: Palgrave Macmillan.

Volet, S. E., \& Ang, G. (1998). Culturally mixed groups on international campuses: An opportunity for intercultural learning. Higher Education Research \& Development, 17(1), 5-23. https://doi.org/10.1080/0729436980170101

Woolf, S. (2008). The meaning of translational research and why it matters. Journal of the American Medical Association, 299(2), 211-213.http://dx.doi.org/10.1001/jama.2007.26 


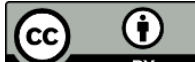

Copyright for the content of articles published in Teaching \& Learning Inquiry resides with the authors, and copyright for the publication layout resides with the journal. These copyright holders have agreed that this article should be available on open access under a Creative Commons Attribution License 4.0 International (https://creativecommons.org/licenses/by/4.0). The only constraint on reproduction and distribution, and the only role for copyright in this domain, should be to give authors control over the integrity of their work and the right to be properly acknowledged and cited, and to cite Teaching \& Learning Inquiry as the original place of publication. Readers are free to share these materials-as long as appropriate credit is given, a link to the license is provided, and any changes are indicated. 